\title{
Nitel Araştırmaların Raporlanmasında Standartlar: SRQR Kontrol Listesinin Türkçe Uyarlaması
}

\author{
DOI: $10.26466 /$ opus.882177
}

*

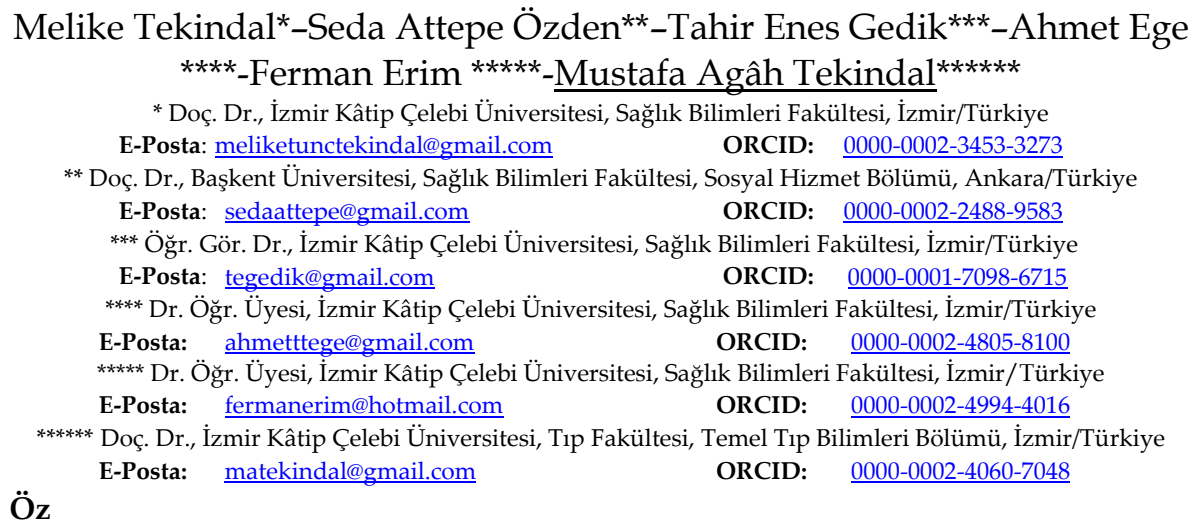

Amaç: Bu çalışmada, Standards for Reporting Qualitative Research (SRQR) kontrol listesinin Türkçe literatürde yer alan nitel araştırmalardaki kullanım alanının genişletilmesi ve standartlara erişimin yaygınlaştırılması amaçlanmıştır. Bu amaçla SRQR kontrol listesinin Türkçe'ye çevirisi yapılmış ve standartlarm Türkçe'ye uygunluğu sağlanmıştır. Gereç ve Yöntem: SRQR kontrol listesi birbirinden bağımsız üç araştırmacı tarafindan Türkçe'ye çevirisi yapılmıştır. Bağımsız çeviriler tüm çeviren kişilerin görüş birliği ile birleştirilmiştir. Sonrasında uzman tarafindan tekrar İngilizce'ye çeviri (ters çeviri) işlemi yapılmıştır. Listeye uygunluğu incelenmiştir. Türkçe SRQR kontrol listesinin tekrarlanabilirliğini ve araştırmacilar tarafindan doğru anlaşılıp anlaşılmadığın değerlendirmek için, iki yazar tarafindan nitel araştırma yöntemi kullanılarak gerçekleştirilen 20 çalışma incelenmiştir. Araştırmacilar arasındaki uyuma bakılmıştır. Kontrol listesindeki her bir kriter için araştırmacılar arası uyum yüzdesi kullanılmıştır. BlandAltman yöntemi ve sınıf içi korelasyon katsayısı ile toplam raporlanan kriter sayısı kullanılarak da uyum değerlendirilmiştir. Bulgular: Araştırma kapsammnda değerlendirmeye alınan araştırmalara göre kriterler, raporlama sıklı̆̆ında büyük bir farklllaşma göstermektedir. SKK değerleri \%44,1 ile \%87,7 değerleri aralığında değişmektedir. Sonuç: Türkçe'ye uyarlanmış olan SRQR kontrol listesi, dergilerin hakemleri ve editörleri ile nitel araştırma yapan araştırmacılar için bir rehber olacaktır.

Anahtar Kelimeler: Nitel Araştırma, SRQR, Sınıf İçi Korelasyon Katsayısı, Bland-Altman Metodu. 


\title{
Standards for Reporting Qualitative Research: Turkish Adaptation of the SRQR Checklist
}

\begin{abstract}
Objective: In this study, we translated and adapted into Turkish the Standards for Reporting Qualitative Research (SRQR), a checklist used in reporting qualitative research. Our aim is to expand the use of the SRQR checklist and make it more accessible. Materials and Methods: Three authors ( $3 r d, 4$ th, and 5 th in author order) translated the SRQR checklist into Turkish independently. The translation was finalized with the consensus among the authors who translated the checklist. Afterwards, an expert back translated and examined the checklist. To evaluate the reproducibility and intelligibility of the Turkish $S R Q R$ checklist, 1st and 2 nd authors reviewed 20 studies which used qualitative research methods. Then, the similarity between the 1 st and 2 nd authors' reviews was examined using the inter-rater agreement percentage for each criterion in the checklist. The inter-rater agreement was further evaluated using the Bland-Altman method, the intraclass correlation coefficient (ICC), and the total number of reported criteria. Results: According to the review of 20 studies, there is a large variation in reporting the SRQR criteria. ICC values range from 44.1 to 87.7. Conclusion: The Turkish SRQR checklist can serve as a guide for the reviewers, journal editors, and researchers who conduct qualitative research.
\end{abstract}

Key Words: Qualitative Research, SRQR, Intra-Class Correlation Coefficient, Bland-Altman Method. 


\section{Giriş}

Nitel araştırma bir problemin ya da konunun keşfedilmesi için kullanılır. Bu keşfin içeriğindeki kolay ölçülemeyen değişkenleri inceleme, bastırılmış seslerin ortaya çıarılması amacıyla gerçekleştirilir.Nitel araştırmalar, anlamı ve deneyimi ortaya çıkarma, görünür kılma, hikaye oluşturma, güçlenme, teori oluşturma, nedenselliğin sorgulanması amacı ile gerçekleştirilebilir. Bu nedenle nitel araştırmalar bireylerin algılarını, deneyimlerini ve gözlemlerini içeren ve deneyim odaklı, araştırma türüdür. Katılımcıların seslerini, araştırmacının derin düşünümlerini, problemin çok boyutlu açıklanmasını ve yorumlamasını, literatüre katkısını ve söylemlerini içerir (Creswell, 2013a, Denzin ve Linkoln, 2005). Bu amaçların gerçekleştirilmesi için de farklı veri toplama yöntemlerini bir arada kullanır. Derinlemesine görüşmeleri, odak grup görüşmelerini, gözlemleri, doküman incelemeleri ve diğer veri türlerini kapsamaktadır (Creswell, 2013a, Patton, 2014, Creswell, 2013b, Kümbetoğlu, 2008, Yüksel, vd., 2007, Marying, 1996, Maxwell, vd. 2009). Nitel araştırmada amaç ve veri toplama çeşitliliği ile birlikte yaklaşım farklılıkları da bulunmaktadır. Nitel araştırmacıların kullanacakları yaklaşımlar içinde fenomenoloji, anlatı, kuram oluşturma, durum, etnografi gibi farklı yaklaşımları bulunmaktadır (Creswell, 2013a, Neuman, 2006). Araştırmacılar nitel araştırma tasarımı yürütürken bu yaklaşımlardan birini tercih etmektedirlerler (Tekindal ve Uğuz-Arsu, 2020).

Araştırmacılar hem yaklaşımlarını ve veri toplama yöntemlerini seçerken hem de derinlemesine çalışma içinde araştırmalarını yazılı hale getirirken karışıklık yaşayabilirler. Bu yaşanan karışıklık ile birlikte bir araştırma raporunda olması gereken bilgileri vermeyi unutabilirler ya da gözden kaçırabilirler. Bu nedenle nitel araştırmalarda farklı alanlarda farklı yazımların birlikteliğini sağlamak zor olmaktadır. Nicel araştırma yöntemlerinde farklı yaklaşımlar için birlikteliği sağlamak, standardı geliştirmek için birçok kontrol listesi bulunurken (Elm, vd., 2007, EQUATOR, 2021, O'Brien, vd. 2014, Malterud, 2001, Levitt, 2018, Rowan ve Huston, 1997) bu durum nitel araştırmalar kapsamında kısıtlıdır. Nitel araştırmaların kalitesinin geliştirilmesi için nitel araştırma raporlarının yazımında standartın geliştirilmesi önemli bir konudur (Kitto, vd., 2008), gereklilik 
birçok yazar tarafından belirtilmektedir (Dunt ve McKenzie, 2012, Barbour, 2001, Bordage ve Caelleigh, 2001, Mays ve Pope, 2000). Bu konuya ilişkin yapılan çalışmalarda yazarlar genellikle yazımda dikkat edilmesi gereken konuları beyan etseler de bu beyanları standart hale getiren araştırma sayısı oldukça azdır (Côté ve Turgeon, 2005, Inui ve Frankel, 1991). $\mathrm{Bu}$ listelerin gerekliliği hem sağlık alanında hem de sosyal bilimler alanında ön plana çıkmaktadır.

Sosyal bilimler alanında öncelikli olarak gelişim gösteren nitel araştırma, sağlık bilimleri alanında da sıklıkla kullanılmaya başlamıştır (Knafl ve Howard, 1984). Farklı alanlarda farklı amaçlarla kullanılan nitel araştırmanın inanılırlığını arttırmak için uluslararası geçerliği olan kuralların bir dizi haline getirilmesi, araştırmacıların da yazımlarını raporlaştırırken gerekli ve önemli konuları gözden kaçırmamalarını sağlayacaktır. Nitel araştırmalarda başlangiçtan sonuca kadar geçen süreç çok önemlidir. Hem araştırmacıların raporlaştırma sürecini kolaylaştırmak hem de yapılan çalışmaların inanılırlığını ve doğruluğunu arttırmak için hali hazırda var olan kontrol listelerinin yaygınlaştırılması bir ihtiyaç olarak karşımıza çıkmaktadır.

Eğitimde nicel araştırmaların raporlanma standartları (Newman ve Elbourne, 2004), gözlemsel çalışmaların raporlaştırılmasında ve (Elm, vd., 2007, Davidoff, vd. 2008, Schulz, vd., 2010), tanı doğruluğu çalışmalarında (Demir, vd., 2019) kullanılmıştır. Bunlarla birlikte nitel araştırmanın raporlaştırılması için bu süreçte birçok farklı liste geliştirilmiştir ( $\mathrm{O}^{\prime}$ Brien, vd. 2014, Malterud, 2001, Levitt, 2018, Tong, vd., 2007, Tracy, 2010, Lincoln, 1995, Burns, 1989, Clark, 2003). Temelde kontrol listeleri giriş, yöntem, analiz ve sonuca yönelik olarak ortak kriterler oluşturmayı amaçlamaktadırlar. Bu bağlamda Tong, Sainsbury ve Craig (2007) tarafından görüşme ve odak grup çalışmaları için kontrol listesi (COREQ) geliştirilmiştir. Ayrıca APA formatına göre beyan edilmiş listeler de bulunmaktadır (Levitt, 2018).

Bu çalışmada, tüm bilim alanlarında, nitel araştırmanın farklı yaklaşımları ve veri toplama yöntemleri için kullanılabilir olan O'Brien ve diğerleri (2014) tarafından geliştirilen "Nitel Araştırmaları Raporlaştırma Standartları (SRQR)" kullanılmıştır. Belirtilen bu standartlar listesinde nitel araştırma raporlarında bulunan başlık özet, giriş, yöntem, bulgular-sonuç, tartışma ve diğer konulara ilişkin 21 standart yer almaktadır. Hem 
tüm yaklaşım ve yöntemleri içermesi hem de geniş kapsamlı olması ve tüm yönlerinin şeffaflığını geliştirmeyi amaçlaması nedeniyle SRQR'un Türkçe versiyonunun geliştirilmesini ve daha anlaşılır olmasını sağlamak hedeflenmiştir. Bu bağlamda araştırmanın amacı nitel araştırmaların yazımında ve raporlanmasında standart oluşumunu sağlayan SRQR kontrol listesinin Türkçe uyarlamasını yapmaktır.

\section{Yöntem}

Araştırmanın amacını gerçekleştirmek için öncelikle SRQR kriterlerinin dil eşdeğerliği yapılmış, sonrasında ilgili makaleleler belirlenen kriterlere göre seçilip bağımsız değerlendiriciler tarafından SRQR kriterlerine göre değerlendirerek değerlendiriciler arası tekrar edilebilirlik analiz edilmiştir.

\section{Dil Eşdeğerliği Çalışması}

Araştırmada ilk olarak dil eş değerliği çalışması yapılmıştır. Bu kapsamda SRQR kontrol listesi üç araştırmacı tarafından Türkçeye çevirilmiştir. Bu çeviri sürecinde araştırmacılar birbirlerinden bağımsız olarak işlemi gerçekleştirmişlerdir. Çeviri aşamasında 2014 yılında SRQR grubu tarafından yayınlanan ve her bir maddenin örneklerle açıklandığı makaleden yararlanılmıştır. Çeviri sonrası araştırmacılar bir araya gelip tüm maddeler üzerinde değerlendirmede bulunarak SRQR kontrol listesinin son Türkçe halinde karar kılmışlardır. Son hali üzerinden çevirmen tarafından İngilizce ve Türkçe versiyonları kontrol edilerek SRQR'un Türkçe kontrol listesi oluşturulmuştur. Türkçe uyarlaması yapılan SRQR, geri çevirme yöntemi ile bir başka uzman çevirmen tarafından Türkçe'den İngilizce'ye çevrilmiş, SRQR kontrol listesinin orijinal versiyonu ile karşılaştırılmıştır. Nitel araştırmaların raporlanmasında kullanılan SRQR kontrol listesinin Türkçe versiyonu Tablo 1'de ve sürecin akış diyagramı Şekil 1'de yer almaktadir. 
Tablo 1. Nitel araştırmaların raporlanmasında kullanılan SRQR kontrol listesinin Türkçe uyarlaması

\begin{tabular}{|c|c|c|}
\hline Sayı & Konu & Madde \\
\hline \multicolumn{3}{|c|}{ Başlık ve Özet } \\
\hline S1 & Başlık & $\begin{array}{l}\text { Çalışmanın doğası ve konusunun özlü bir şekilde açıklanması. Çalışmanın nitel olduğunun, yak- } \\
\text { laşımının (örn., etnografi, gömülü teori) veya veri toplama yönteminin (örn., görüşme, odak grup) } \\
\text { belirtilmesi tavsiye edilmektedir. }\end{array}$ \\
\hline S2 & Özet & $\begin{array}{l}\text { Çalışmanın temel öğelerinin, hedeflenen yayının özet formatına uygun şekilde sunulması; genel- } \\
\text { likle arka plan, amaç, yöntem, bulgular ve sonuçları içerir. }\end{array}$ \\
\hline \multicolumn{3}{|r|}{ 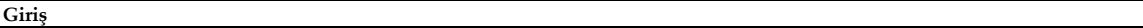 } \\
\hline S3 & $\begin{array}{l}\text { Problemin oluşturul- } \\
\text { ması }\end{array}$ & $\begin{array}{l}\text { Çalışılan problemin/fenomenin tanımlanması ve önemi; ilgili kuram ve ampirik çalışmaların göz- } \\
\text { den geçirilmesi; problemin ifade edilmesi }\end{array}$ \\
\hline S4 & $\begin{array}{l}\text { Amaç veya araştırma } \\
\text { sorusu }\end{array}$ & Çalışmanın amacı ve belirgin hedefler veya sorular \\
\hline \multicolumn{3}{|c|}{ Yöntem } \\
\hline S5 & $\begin{array}{l}\text { Nitel yaklaşım ve araş- } \\
\text { tırma paradigması }\end{array}$ & $\begin{array}{l}\text { Nitel yaklaşım (örn., etnografi, gömülü teori, vaka çalışması, fenomenoloji, anlatı araştırması) ve } \\
\text { eğer varsa, yol gösteren kuram; araştırma paradigmasının (örn., post-pozitivist, yapılandır- } \\
\text { macı/yorumsamacı) belirtilmesi de önerilmektedir; gerekçeler }{ }^{b}\end{array}$ \\
\hline S6 & $\begin{array}{l}\text { Araştırmacının özellik- } \\
\text { leri ve düşünümsellik }\end{array}$ & $\begin{array}{l}\text { Araştırmacının, kişisel nitelikleri, vasıfları/deneyimleri, katılımcılarla ilişkileri, varsayımları } \\
\text { ve/veya ön kabulleri gibi araştırmayı etkileyebilecek özellikleri; araştırmacının özellikleri ve araş- } \\
\text { tırma soruları, yaklaşımlı, yöntemleri, sonuçları ve/veya aktarılabilirliği arasındaki potansiyel ya } \\
\text { da halihazırdaki etkileşim }\end{array}$ \\
\hline S7 & Bağlam & Saha/mekân ve göze çarpan bağlamsal faktörler; gerekçeler ${ }^{\mathrm{b}}$ \\
\hline S8 & Örnekleme stratejisi & $\begin{array}{l}\text { Katılımcılar, belgeler ve olaylar nasıl ve neden seçildi; daha fazla örnekleme gerekmediğine dair } \\
\text { karar kriteri (örn., örnekleme doygunluğu); gerekçeler }{ }^{\text {b }}\end{array}$ \\
\hline S9 & $\begin{array}{l}\begin{array}{l}\text { Katılımcılara } \\
\text { etik konular }\end{array} \\
\end{array}$ & $\begin{array}{l}\text { Etik kurul onayının ve katılımcıların rızasının alındığına dair belgeler, ya da yoksa neden olmadı- } \\
\text { ğının açıklaması; diğer gizlilik ve veri güvenliği konuları }\end{array}$ \\
\hline S10 & $\begin{array}{l}\text { Veri toplama yöntem- } \\
\text { leri }\end{array}$ & $\begin{array}{l}\text { Toplanan veri türleri; veri toplama ve analizin başlangıç ve bitiş tarihleri, tekrarlama süreci, kay- } \\
\text { nakların/yöntemlerin üçgenlenmesi (triangulation) ve ortaya çıan çalışma bulgularına göre pro- } \\
\text { sedürlerin değiştirilmesi de dahil olmak üzere veri toplama yöntemlerinin detayları; gerekçeler }\end{array}$ \\
\hline S11 & $\begin{array}{l}\text { Veri toplama araçları } \\
\text { ve teknolojileri }\end{array}$ & $\begin{array}{l}\text { Veri toplamada kullanılan araçların (örn., görüşme kılavuzu, soru formu) ve cihazların (örn., ses } \\
\text { kayıt cihazı) açıklanması; eğer değiştilerse, çalışma boyunca kullanılan araçlar nasıl değişti }\end{array}$ \\
\hline S12 & Çalışma birimleri & $\begin{array}{l}\text { Çalışmaya dahil edilen katılımcıların, belgelerin ve olayların sayısı ve ilgili özellikleri; katılım dü- } \\
\text { zeyi, örn., katılım sayısı, farklı veri toplama yöntemleri/tekniklerinde bulunma durumu (bulgular } \\
\text { bölümünde de rapor edilebilir) }\end{array}$ \\
\hline S13 & Verinin işlenmesi & $\begin{array}{l}\text { Deşifre, veri girişi, verilerin yönetilmesi ve güvenliği, veri bütünlüğü, kodlama ve alıntıları ano- } \\
\text { nimleştirme/kimlik gizleme gibi analiz öncesi ve sırasında gerçekleştirilen veri işlemleri }\end{array}$ \\
\hline S14 & Veri analizi & $\begin{array}{l}\text { Çıkarımların, temaların vs. tanımlandığı ve geliştirildiği, hangi araştırmacıların analize katkıda } \\
\text { bulunduğunun açıklandığı süreç; genellikle belli bir paradigmaya veya yaklaşıma referans verilir; } \\
\text { gerekçeler }^{\text {b }}\end{array}$ \\
\hline S15 & $\begin{array}{l}\text { İnanılırlığı arttıracak } \\
\text { teknikler }\end{array}$ & $\begin{array}{l}\text { Veri analizinin inanılırlığını ve inandırıcılığını arttıran teknikler (örn., katılımcı kontrolü, veri top- } \\
\text { lama ve analizin denetlenebilirliği (audit trail), üçgenleme); gerekçeler }{ }^{b}\end{array}$ \\
\hline \multicolumn{3}{|c|}{ Sonuçlar/Bulgular } \\
\hline S16 & Sentez ve yorum & $\begin{array}{l}\text { Ana bulgular (örn., yorumlar, çıkarımlar ve temalar); bir kuram ya da model geliştirmeyi veya } \\
\text { önceki araştırma ve kuramlarla birleştirmeyi/bütünleştirmeyi içerebilir. }\end{array}$ \\
\hline S17 & $\begin{array}{l}\text { Ampirik veriyle bağ- } \\
\text { lantılar }\end{array}$ & $\begin{array}{l}\text { Analitik bulguları desteklemek için kanıtlar (örn., alıntılar, saha notları, metinlerden parçalar, fo- } \\
\text { toğraflar) }\end{array}$ \\
\hline \multicolumn{3}{|r|}{ (2: } \\
\hline S18 & $\begin{array}{l}\text { Önceki çalışmalarla bü- } \\
\text { tünleştirme, çıarımlar, } \\
\text { aktarılabilirlik ve alana } \\
\text { katkı(lar) }\end{array}$ & $\begin{array}{l}\text { Ana bulguların kısa bir özeti; mevcut bulguların ve sonuçların önceki çalışmaların sonuçlarına } \\
\text { nasıl bağlandığının, bu sonuçları nasıl desteklediğinin ve geliştirdiğinin veya bu sonuçlarla nasıl } \\
\text { ters düştüğünün açıklanması; uygulama/genellenebilirlik kapsamının tartışlması; disipline ya da } \\
\text { alana yapılan özgün katkının belirlenmesi }\end{array}$ \\
\hline S19 & Sinırlılıklar & Bulguların inanılırlığı ve sınırlılıkları \\
\hline \multicolumn{3}{|c|}{ Diğer } \\
\hline S20 & Çıkar çatışması & $\begin{array}{l}\text { Yürütülen çalışmanın üzerindeki, çıkar çatışmasına sebep olabilecek potansiyel ve algılanan etki } \\
\text { kaynakları; bunlar nasıl yönetildi }\end{array}$ \\
\hline S21 & Fonlama & $\begin{array}{l}\text { Fon ve diğer destek kaynakları; fon sağlayıcıların veri toplama, yorum ve raporlama sırasındaki } \\
\text { rolü }\end{array}$ \\
\hline
\end{tabular}


aYazarlar, nitel araştırma için kılavuzlarını, raporlama standartlarını ve eleştirel değerlendirme kriterlerini belirlemek için literatürde arama yaparak, alınan kaynakların referans listelerini gözden geçirerek ve geri bildirim almak için uzmanlarla iletişim kurarak SRQR'1 oluşturdular. SRQR, nitel araştırmanın raporlanması için net standartlar sağlayarak nitel araştırmanın tüm yönlerinin şeffaflı̆̆ını geliştirmeyi amaçlamaktadır.

${ }^{b}$ Gerekçelerde kısaca neden diğer seçenekler yerine mevcut kuramın, yaklaşımın, yöntemin ya da tekniğin tercih edildiği, bu tercihlere içkin olan varsayımlar ve sinırlılıklar ve bu tercihlerin nasıl sonuçları ve aktarılabilirliği etkilediği tartışılmalıdır. Uygun olduğu takdirde birkaç maddenin gerekçesi bir arada tartışılabilir.

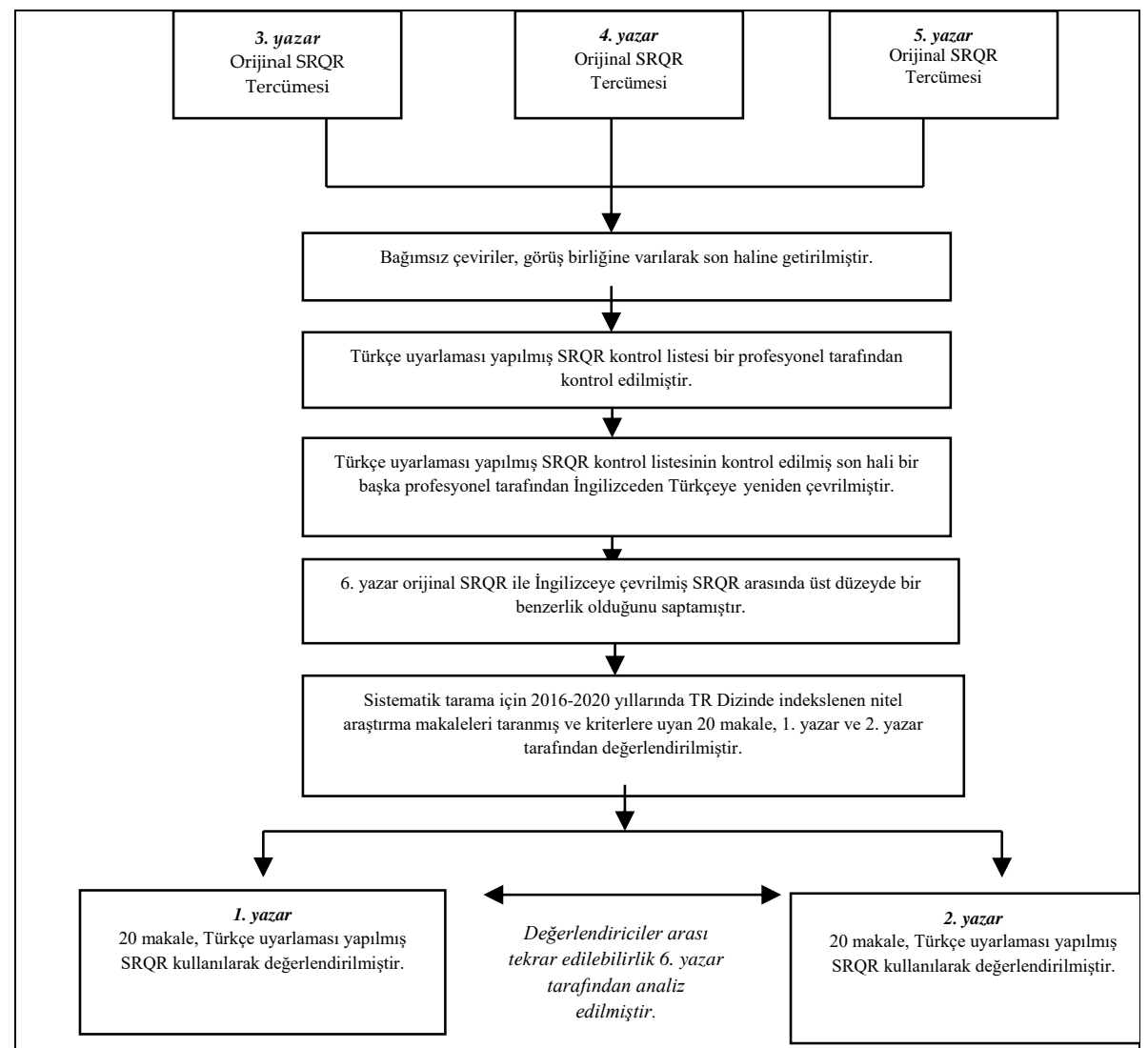

Şekil 1. Nitel çalışmaların raporlanmasında kullanılan SRQR kontrol listesinin Türkçe uyarlamasında izlenen akış diyagramı 
Araştırmada ikinci olarak Türkçeye uyarlanmış SRQR kontrol listesinin tekrar edilebilirlik düzeyini ve araştırmacılar tarafından doğru bir şekilde anlaşılıp anlaşılmadığı değerlendirilmiştir. Bunun için öncelikli olarak makale seçimi sonrasında seçilen makalelerin değerlendirmesi yapılmiştır.

\section{Makale Seçimi ve Makalelerin Değerlendirilmesi}

Araştırma kapsamında değerlendirmeye alınacak makaleler için 12 Ocak 2021 tarihinde yapılan tarama kriterleri; ULAKBİM TR Dizin'de yer alması, 2016-2020 yıllarında yayınlanması, yayın dili Türkçe olmasıdır. Ayrıca başlık, özet ya da anahtar kelimelerinde, "nitel araştırma”, "niteliksel araştırma", "kalitatif araştırma" kelimelerinin en az birinin yer alması kriter olarak belirlenmiştir. Bu tarama kriterlerini sağlayan toplam makale sayısı ilk etapta 487 olarak bulunmuş daha sonra yazar (6. yazar) tarafından makalelerin tümü değerlendirilmiş ve nitel çalışma olmadığı tespit edilen 122 makale elenmiştir. Eleme sonucunda 20 makale belirlenmiştir. Seçilen 20 makale yazarların içinde seçilen iki (1. yazar ve 2. yazar) bağımsız araştırmacı tarafından çift kör olacak şekilde değerlendirilmiştir. Bu nedenle öncelikle belirlenen 20 makalenin değerlendirilmesi için birbirinden bağımsız olarak iki araştırmacı SRQR kriterlerinin Türkçe versiyonunu kullanmışlardır. SRQR kontrol listesinin her bir maddesi ve ilgili makaleler Excel dosyasına işlenerek değerlendirilmiştir. Bu değerlendirmenin temel amacı, değerlendiriciler tarafından maddelerin benzer şekilde algılanıp algılanmadığı belirlemek için uyuma bakılmasıdır. Her iki araştırmacı da değerlendirmelerini aynı zaman dilimi içerisinde gerçekleştirmişlerdir. Makalelerin değerlendirmesi yaklaşık bir hafta sürmüştür. Bunlarla birlikte ilgili araştırma etik kurul izni gerektiren bir çalışma olmadığı için etik kurul izni alınmamıştır.

\section{İstatistiksel Yöntemler}

Her bir araştırmacı, belirlenen 20 makaleyi değerlendirirken oluşturulan excel dosyası üzerinde her bir makale için, SRQR kontrol listesinde yer 
alan her bir maddeye " 0 " veya " 1 " verilerek puanlandırma yapmıştır. Verilen "1" puanı söz konusu maddenin tamamının incelenen makalede yer aldığını, " 0 " puanı ise incelenen makalede yer almadığını göstermektedir. $\mathrm{Bu}$ şekilde SRQR kriterlerinde yer alan her bir madde puanlandıktan sonra, her bir makale için bir toplam puan elde edilmiştir. Elde edilen bu toplam puanlar her bir makale için sağlanan toplam madde sayısını bildirmektedir. Bu şekilde her bir araştırmacının kendi değerlendirme puanları oluşmuştur.

Değerlendiriciler arası tekrarlanabilirliği ölçmek için Bland-Altman yöntemi kullanılarak makalelere verilen toplam puanlar karşılaştırılmıştır. Bu yöntem ile iki değerlendiricinin SRQR kriterlerini kullanarak makalelere verdiği puanlar arasındaki farkın dağılımı incelenmiştir (Schmidt ve Steindorf, 2006). Bu farkların ortalaması ve standart sapması hesaplanarak değerlendiriciler arası uyum ölçülmüştür. Standart sapmanın azalması ve farkların ortalamasının sıfıra yaklaşması değerlendiriciler arası uyumun arttığına işaret etmektedir. Değerlendirmecilerin puanları arasındaki farklılıklara göre uyumu belirlemek için Bland-Altman grafiği çizilmiştir. SRQR kontrol listesinin Türkçe versiyonuna göre çizilen bu grafiğin eksenlerine, değerlendiriciler tarafından verilen puanlar arasındaki farklar ve değerlendiricilerin her bir makaleye verdiği puanların ortalamaları atanmıştır. İki ölçüm tekniğini karşılaştıran ve grafiksel bir istatistiksel metot olan Bland-Altman yönteminde iki teknik arasındaki fark, iki yöntemin ortalamalarına göre $\% 95$ güven sinırlarında belirlenen sapmalar çizilerek karşılaştırılmıştır (Albayrak, vd., 2012; Balak, vd., 2018; Tekindal, vd. 2015).

Yapılan değerlendirmelerden her bir makalenin en yüksek 24 puan alabileceği belirlenmiştir. Her bir makalenin puan ortalaması ve standart sapmasına yer verilmiştir. Bunlarla birlikte araştırmaya dahil edilen her bir makalenin SRQR kriterlerine uygun olarak raporlanma durumunun değerlendiriciler tarafından ayırt edilme düzeyinin belirlenmesi için sınıf içi korelasyon katsayısı (SKK)'ndan yararlanılmıştır. SKK' nın 0.75' in üzerinde olması ideal olmakla birlikte bu katsayı 0 ile +1 aralığında değişmektedir (Lee, vd. 1989; McGraw ve Wong, 1996). Ayrıca SKK'nın hesaplanması için iki yönlü rastgele etkili model ve mutlak uyum seçeneği (Twoway random effect models) kullanılmıştır (Albayrak vd., 2012; Ateş, vd., 2009). 


\section{Bulgular}

Nitel araştırma raporlarının yazımı için geliştirilen, Türkçeye uyarlanmış SRQR kontrol listesine ilişkin SKK değerleri Tablo 2' de verilmiştir. Tüm makalelerde değerlendirmeciler arası uyum istatistik olarak anlamlı bulunmuştur $(\mathrm{p}<0,05)$.

Tablo 2. Türkçeye uyarlanmış SRQR kontrol listesi için SKK değerleri

\begin{tabular}{lll}
\hline Madde No & $\begin{array}{l}\text { Sinıf içi Korelasyon Katsayısı (SKK) } \\
\text { (\%95 GA) }\end{array}$ & p \\
\hline 1 & $1,000(1,000-1,000)$ & 0,001 \\
2 & $0,791(0,472-0,917)$ & 0,001 \\
3 & $0,791(0,472-0,917)$ & 0,003 \\
4 & $0,731(0,319-0,893)$ & 0,001 \\
5 & $0,877(0,688-0,951)$ & 0,013 \\
6 & $0,654(0,125-0,863)$ & 0,035 \\
7 & $0,574(0,077-0,831)$ & 0,012 \\
8 & $0,656(0,130-0,864)$ & 0,043 \\
9 & $0,494(0,278-0,800)$ & 0,041 \\
10 & $0,485(0,255-0,756)$ & 0,047 \\
11 & $0,441(0,212-0,752)$ & 0,044 \\
12 & $0,434(0,135-0,697)$ & 0,021 \\
13 & $0,421(0,263-0,771)$ & 0,042 \\
14 & $0,556(0,122-0,824)$ & 0,044 \\
15 & $0,558(0,381-0,627)$ & 0,041 \\
16 & $0,494(0,290-0,641)$ & 0,001 \\
17 & $0,877(0,690-0,951)$ & 0,040 \\
18 & $0,519(0,216-0,809)$ & 0,040 \\
19 & $0,561(, 0110-0,826)$ & - \\
20 & $1,000(1,000-1,000)$ & 0,001 \\
21 & $0,526(0,187-0,604)$ & \\
\hline
\end{tabular}

SRQR kontrol listesine göre değerlendirilen 20 makalede iki değerlendiricinin de Madde 20 ve Madde 1'in ise bu makalelerde hiç raporlanmadığını tespit etmişlerdir. Bu anlamda SRQR kontrol listesine uyum bakımından varyasyon aralığının fazla olduğu belirlenmiştir. Yapılan değerlendirme sonucunda bütün SRQR kontrol listesini tümüyle sağlayan bir makaleye rastlanmamıştır. SKK değerleri \%44,1 ile \%87,7 değerleri aralığında değişmektedir. 
Tablo 3. Türkçe'ye uyarlanmış SRQR kontrol listesi için Bland-Altman Grafiği için tanımlayıcı istatistikler

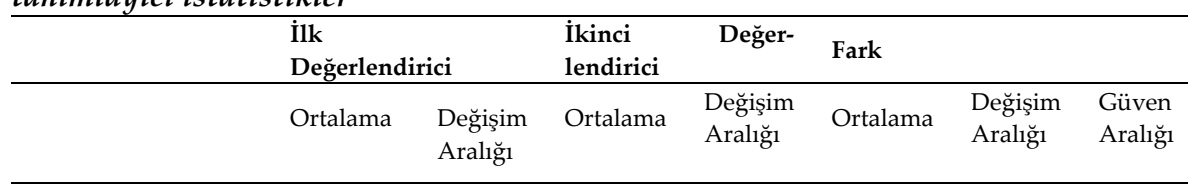

SRQR kontrol

listesine göre ma-

kalelerin aldığı pu-

anlar

10,2

$3-19$

13,1

8-17

$-2,95$

$-8 ; 2$

$-4,39$;

1,51

Tablo 3'te görüldüğ ü gibi makalelere verilen toplam puanların ortalama ve değişim aralıkları, değerlendiriciler arası farkların ortalaması, standart sapması ve güven aralıkları görülmektedir. Makalelerin aldığ 1 puanların ortalaması yaklaşık 12,7 olarak hesaplanmıştır. Ayrıca, farklara ilişkin güven aralıkları sıfırı içerdiği için yapılan değerlendirmelerde yanlılı̆̆ın olmadığı sonucuna varılmıştır.

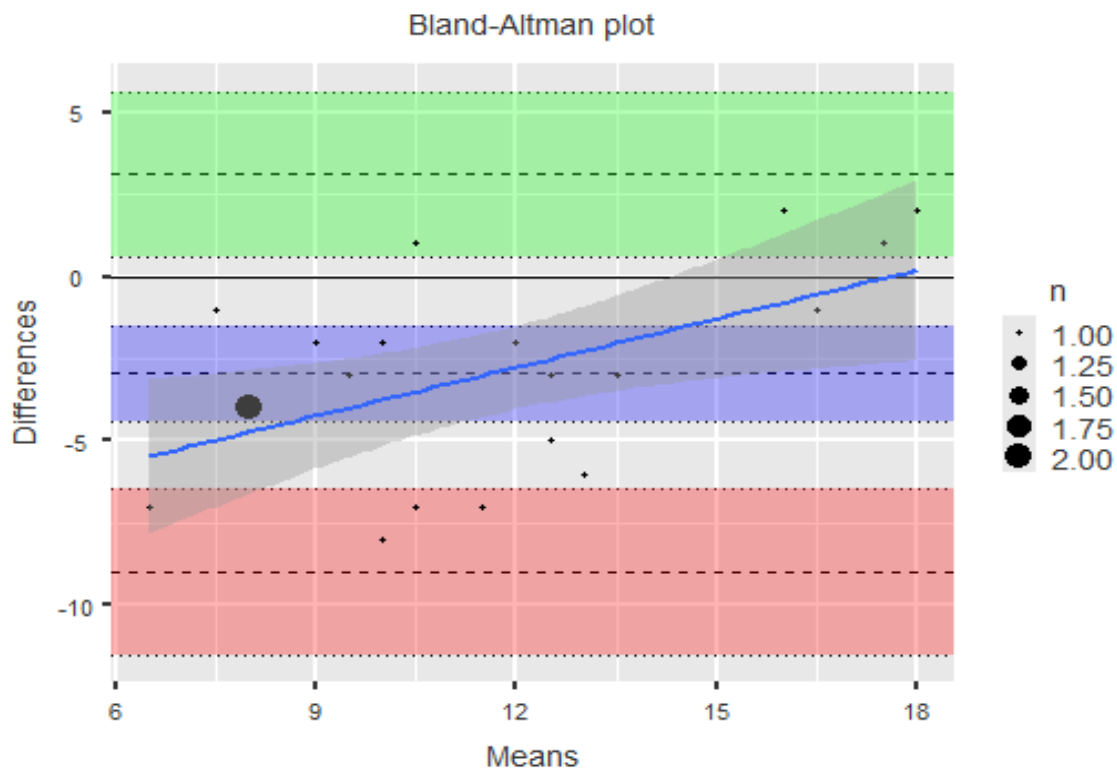

Şekil 2. Türkçeye uyarlanmış SRQR kontrol listesi için değerlendiricilerin makalelere verdiği puan ortalamalarına (x ekseni) ve değerlendiriciler arasında farklara (y ekseni) göre çizdirilen Bland-Altman Grafiğ i 
Şekil 2'deki grafikte değerlendiriciler arası farklar dikkate alınarak Bland-Altman grafiği çizilmiştir. Grafikte SRQR kontrol listesine göre yapılan değerlendirmede makalelerin aldığı ortalama puanlar $\mathrm{X}$ ekseninde, çalışmalara verilen toplam puanlar bakımından değerlendiriciler arasındaki farklar ise $Y$ ekseninde gösterilmiştir. Türkçeye uyarlanmış SRQR kontrol listesine göre makalelerin aldıkları puanlar 3-19 arasında değiş̧mektedir.

\section{Tartışma ve Sonuç}

Çalışmanın amacı nitel araştırmalarda kullanılan SRQR kontrol listesinin Türkçeye uyarlamasını yaparak, yazarlara, okuyuculara ve değerlendiricilere kullanacakları Türkçe ehberi sunmaktır. İlgili standartların Türkçe' de de kullanımın yaygınlaşması ve ulaşılabilir olması amacını taşımaktadır. Bu bağlamda bu standartların nitel çalışmaların yazımında kullanılacak olması sayesinde nitel araştırma raporlarındaki eksiklikleri gidereceği ve araştırmacılar ve okuyuculara yol göstereceği düşünülmektedir.

$\mathrm{Bu}$ amaçla yapılan araştırmada SRQR kontrol listesinin değerlendiriciler arası uyumunun anlamlı olduğu sonucuna varılmıştır. Ayrıca araştırma kapsaminda incelenen makalelerin standartlardan aldıkları toplam puanlar ortalama değerin altındadır. Bu sonuç bize araştırma kapsamında incelenen makalelerde ilgili standartlara ait bilgilerin yeterli düzeyde yer almadığını göstermektedir.

Bilinmektedir ki nitel araştırmaların raporlanmasında başlığın yazımindan başlayarak özetin, girişin, amacın, yöntemin, yönteme ait alt bilgilerin, analizin, sonuç ve tartışmanın yazımı kendine özgüdür. Sürecin önem arz ettiği nitel araştırmalarda tüm sürecin raporlara detaylı şekilde yansıtılması gerekmektedir. İnanılırlığın artması, geçerlilik ve güvenilirliğin sağlanması açısından süreçteki tüm bilgilerin yazıya aktarılması gerekmektedir.

SRQR kontrol listesinin amacı da nitel araştırmaları raporlarken tüm yönleriyle şeffaflığı sağlamaktır. Makale hazırlarken yazarlara, makale değerlendirmesinde hakemlere, analiz ve sonuçların eleştirel değerlendirilmesinde okuyuculara yardımcı olmaktır (O'Brien vd., 2014). SRQR kontrol listesinin ilk bölümünde başlık, özetin yazımına ait standartlar bulunmaktadır. İkinci bölümünde giriş; problemin oluşturulması, amaç ve 
amaç sorularına yönelik standartlar bulunmaktadır. Üçüncü bölümünde yöntem; nitel yaklaşım ve paradigma, araştırmacının özellikleri ve düşünümsellik, bağlam, örnekleme stratejisi, katılımcllara ilişkin etik konular, veri toplama yöntemleri, veri toplama araçları ve yöntemleri, çalışma birimleri, verilerin işlenmesi, verilerin analizi, inanırlığı arttıracak teknikleri içermektedir. Dördüncü bölümünde sonuçlar/bulgular; sentez ve yorum, ampirik veriyle bağlantılar yer almaktadır. Beşinci bölümünde tartışma; Önceki çalışmalarla bütünleştirme, çıkarımlar, aktarılabilirlik ve alana katkı(lar) ve sinırlılıklara ilişkin standartlar yer almaktadır. Altıncı ve son bölümünde çıkar çatışması ve fonlanmaya ilişkin diğer standartlar yer almaktadır. Tüm bu standartlara ilişkin ayrıntılı gerekçelerin de raporlamada belirtilmesinin önemi vurgulanmıştır.

Bu standartlar farklı alanlarda hem görüşme, hem odak grup görüşmesi, hem ikincil kaynakların analizinde, hem de farklı nitel araştırma yöntemlerinin yazımı için kılavuz olarak kullanılabilir.

Belirli uluslararası standartların nitel araştırmaların yazımında kullanılması hem nitel bilginin ve nitel araştırmanın öneminin görünür olmasında etkili olacaktır. Yapılacak ileri araştırmalar için veri kaynağını oluşturabilecektir. 
EXTENDED ABSTRACT

\title{
Standards for Reporting Qualitative Research: Turkish Adaptation of the SRQR Checklist
}

\author{
Melike Tekindal-Seda Attepe Özden-Tahir Enes Gedik-Ahmet Ege- \\ Ferman Erim -Mustafa Agâh Tekindal \\ İmir Katip Çelebi University
}

Qualitative research explores the perceptions and experiences of individuals that are not easily quantified. It emphasizes the sense-making practices of the social actors and the reflexivity of the researcher to interpret these practices. Data sources in qualitative research include natural observations, participant-observations, in-depth interviews, focus groups, texts, and other cultural objects. Scholars follow several distinct methodological approaches such as grounded theory, ethnography, and phenomenology. In other words, qualitative research methods have a rich theoretical background and cover a diverse array of methods and methodologies. Nevertheless, the plurality of the qualitative methods could lead to challenges in analyzing and communicating the findings. Moreover, the researchers might overlook important details of the study and fail to fully report relevant information. To address these issues, some researchers developed checklists for reporting qualitative research such as the Consolidated Criteria for Reporting Qualitative Studies (COREQ). These checklists include several items on research design, methods, and findings as well as ethical issues to increase the transparency of research. Although such checklists have been used in quantitative research for some time, their adoption is rather new in qualitative research.

In this study, we translated and adapted into Turkish the Standards for Reporting Qualitative Research (SRQR). The SRQR consists of 21 item and covers five topics: title and abstract, introduction, methods, results/findings, and discussion. The checklist encourages the researchers to explain the rationale of their decisions under each topic. According to the SRQR checklist, researchers should provide a concise description and key elements of the study in the title and abstract. In the introduction, they need to state the purpose and research questions of the study as well as its wider 
significance. The methods section should be comprehensive and discuss the qualitative approach and research paradigm, characteristics of the researchers (including various sources of bias), context (setting/site), ethical issues pertaining to the participants (e.g., confidentiality and security), data collection methods and relevant instruments/devices (and changes in their use), units of study and characteristics of participants (e.g., demographics), data processing (e.g., anonymization/deidentification), data analysis (with references to the relevant paradigm), and techniques to enhance trustworthiness (e.g., audit trials). In the results section, researchers should present both their main findings and evidence to substantiate them (e.g., quotes, field notes). Finally, researchers should discuss how their findings integrate with the prior work and what their unique contributions are to the extant literature. In this section, they also need to address the limitations of their research and propose what future studies could explore.

Our study has two stages: translation/adaptation and evaluation of the checklist. First, three authors (3rd, 4th, and 5th) translated the SRQR checklist into Turkish independently. The authors decide on the final version by deliberation and consensus. The Turkish version of the checklist was back-translated, compared to the original SRQR checklist, and approved by an expert who is a native speaker of both Turkish and English. In the second stage of the study, 1st and 2nd authors reviewed 20 articles out of 487 that were selected from the ULAKBIM TR Dizin. The selected articles were published between 2016 and 2020 and used qualitative methods. 1st and 2 nd authors scored (" 0 " or " 1 ") the articles for each item on the SRQR checklist. The total scores reflected the total number of items reported in the articles. To assess the reproducibility and inter-rater agreement, 6th author analyzed scores using Bland-Altman method and intraclass correlation coefficient (ICC). ICCs were estimated using two-way random effects models. The results show that there is a large variation in reporting the criteria in the SRQR checklist. ICC values range from 44.1 to 87.7. Bland-Altman method indicates that there is no bias in author evaluations.

Following this analysis, we argue that a limited number of items in the $\mathrm{SRQR}$ checklist is reported in the reviewed articles. This is not ideal, but we suspect that this is a common issue. We claim that researchers should 
use the SRQR checklist to increase the trustworthiness and reliability of their studies, which would also enhance the transparency of their research. In other words, the research procedures would become clear so that journal editors, reviewers, and other researchers could easily evaluate them. The SRQR checklist would also render assessing the merits of studies compared to each other easier. Finally, it leads to a more disciplined approach in the accumulation of knowledge in certain areas of research. By making the SRQR checklist more accessible, we aim to contribute to its wider adoption. We argue that the SRQR checklist can serve as an invaluable guide for those who conduct qualitative research.

\section{Kaynakça/References}

Albayrak, R., Tekindal, M.A., Ateş, C., Selvi, P., Perinçel, S., Ceyhan, K., vd. (2012). Tanı doğruluğu çalışmalarının kalitelerinin değerlendirilmesi: STARD kriterlerinin Türkçe uyarlaması. Ankara Üniversitesi Tıp Fakültesi Mecmuası, 65(3), 137-46.

Ateş, C., Öztuna, D. ve Genç, Y. (2009). Sağlık araştırmalarında sınıf içi korelasyon katsayısının kullanımı. Türkiye Klinikleri J Biostat, 1, 59-64.

Balak, T., Günay, F., Kaymaz, Ö., Çevrimli, M.B., Özen, D. ve Tekindal, M.A. (2018). Veteriner hekimlik alanında gözlemsel araştırmaların rapor edilmesi: STROBE-VET kriterlerinin Türkçe uyarlaması, Eurasian J Vet Sci, 34, 4, 257-264, DOI: 10.15312/EurasianJVetSci.2018.208

Barbour, R.S. (2001). Checklists for improving rigour in qualitative research: A case of the tail wagging the dog? BMJ, 322, 1115-1117.

Bordage, G. ve Caelleigh, A.S. (2001). A tool for reviewers: Review criteria for research manuscripts, Acad Med., 76, 904-951.

Burns, N. (1989). Standards for qualitative research. Nurs Sci Q., 2, 44-52.

Clark, J.P. (2003). How to peer review a qualitative manuscript. In Peer Review in Health Sciences. Second edition. (Eds. Godlee F, Jefferson T.) içinde (s.219-235) BMJ Books: London.

Côté, L. ve Turgeon, J. (2005). Appraising qualitative research articles in medicine and medical education. Med Teach, 27, 71-75.

Creswell, J.W. (2013a). Nitel araştırma yöntemleri: Beş yaklaşıma göre nitel araştırma ve araştırma deseni. Ankara: Siyasal Kitabevi.

Creswell, J.W. (2013b). Araştırma deseni: Nitel, nicel ve karma yöntem yaklaşımları (Çev. Ed: SB Demir). İstanbul: Eğiten Kitap. 
Davidoff, F., Batalden, P., Stevens, D., Ogrinc, G. and Mooney, S. (2008). SQUIRE Development Group. Publication guidelines for quality improvement in health care: Evolution of the SQUIRE project. Qual Saf Health Care,17(suppl 1), 3-9

Demir, E., Yavuz, Y., Ateş, C., Tekindal, M.A., Muslu, Ü. ve Yıldırım, E. (2019). STARD 2015 kriterlerinin Türkçe uyarlaması; tanı doğruluğu çalışmalarının raporlanması için bir kılavuz, Turkiye Klinikleri J Biostat, 11(2), 15260 DOI: 10.5336/biostatic.2019-65010.

Denzin, N. ve Lincoln, Y. (2005). Introduction: The discipline and practice of qualitative research; The Sage Handbook of Qualitative Research. İçinde (s.1-32). Calif Sage Publications: Thousand Oaks.

Dunt, D, ve McKenzie, R. (2012). Nitel araştırmaların kalitesinin iyileştirilmesi: Raporlama yönergelerinin bir yeri var mı? Fam Pract, 29, 367-369.

Elm, E. von, Altman DG, Egger M, Pocock SJ, Gøtzsche PC, Vandenbroucke JP. (2007). Strengthening the reporting of observational studies in epidemiology (STROBE) statement: Guidelines for reporting observational studies. BMJ, 335, 806-808.

Inui, T.S. ve Frankel, R.M. (1991). Evaluating the quality of qualitative research: A proposal pro tem. J Gen Intern Med, 6, 485-486.

Kitto, S.C., Chesters, J. ve Grbich, C. (2008). Quality in qualitative research. Med J Aust, 188, 243-246.

Knafl, K.A. ve Howard, M.J. (1984). Interpreting and reporting qualitative research. Res Nurs Health, 7, 17-24.

Kümbetoğlu, B. (2008). Sosyolojide ve antropolojide niteliksel yöntem ve araştırma. Ankara: Bağlam Yayınclik.

Lee, J., Koh, D. ve Ong, C.N. (1989). Statistical evaluation of agreement between two methods for measuring a quantitative variable. Comput. Biol. Med., 19, 61-70.

Levitt, H. M., Bamberg, M., Creswell, J. W., Frost, D. M., Josselson, R. ve SuárezOrozco, C. (2018). Journal article reporting standards for qualitative primary, qualitative meta-analytic, and mixed methods research in psychology: The APA Publications and Communications Board task force report. American Psychologist, 73(1), 26.

Lincoln, Y.S. (1995). Emerging criteria for quality in qualitative and interpretive research. Qual Inq, 1, 275-289.

Malterud, K. (2001). Qualitative research: Standards, challenges, and guidelines. Lancet, 358, 483-488. 
Marying, P. (1996). Nitel sosyal araştırmaya giriş. Ankara: Bilgesu yayıncılık.

Mays, N. ve Pope, C. (2000). Qualitative research in health care. Assessing quality in qualitative research. BMJ, 320, 50-52.

Maxwell, J.A., Bickman, L. and Bog, D. (2009). Designing a qualitative study. The SAGE Handbook of Applied Social Research Methods. İçinde (s.214-253) 2nd ed Sage Publications, Inc.

McGraw, K.O. ve Wong, S.P. (1996). Forming inferences about some intraclass correlation coefficients. Psychol Methods, 1(1), 30-46.

Newman, M. ve Elbourne, D. (2004). Improving the usability of educational research: Guidelines for the reporting of primary empirical research studies in education (The REPOSE Guidelines). Eval Res Educ, 18, 201-212.

Neuman, Lawrens W. (2006). Toplumsal araştırma yöntemleri nitel ve nicel yaklaşımlar. (Çeviren: Sedef Özge). Ankara: Yayınodası.

O’Brien, Bridget, C., Harris, Ilene, B., Beckman, Thomas J. , Reed, Darcy A., Cook, David A. (2014). MHPE Standards for reporting qualitative research. Academic Medicine, 89(9), 1245-1251.doi: 10.1097/ACM.0000000000000388.

Patton, M.Q. (2014). Nitel araştırma ve değerlendirme yöntemleri. (Çeviri Editörleri: Mesut Bütün ve Selçuk Beşir Demir). Ankara: Pegem Akademi.

Rowan, M. ve Huston, P. (1997). Qualitative research articles: Information for authors and peer reviewers. CMAJ., 157, 1442-1446.

Schmidt, M.E. ve Steindorf, K. (2006). Statistical methods for the validation of questionnaires. Methods of information in medicine, 45(4), 409-413.

Schulz, K.F., Altman, D.G. and Moher, D. (2010). CONSORT Group. CONSORT 2010 statement: Updated guidelines for reporting parallel group randomised trials. BMJ. 340, 332.

Tekindal M. A., Ateș C., Yavuz Y., Albayrak R., Selvi P. (2015). Tanı doğruluğu çalışmalarının stard kriterlerine göre Türk tıp dizini özelinde değerlendirilmesi Ankara Üniversitesi Tıp Fakültesi Mecmuası, 68(2), 49-53. DOI: 10.1501/Tipfak_000000889.

Tekïndal, M. ve Uğuz Arsu, Ş. (2020). Nitel araştırma yöntemi olarak fenomenolojik yaklaşımın kapsamı ve sürecine yönelik bir derleme. Ufkun Ötesi Bilim Dergisi, 20(1) , 153-172.

The EQUATOR Network: Enhancing the quality and transparency of health research. 26.01. 2021 tarihinde http://www.equator-network.org adresinden erişildi. 
Tong A., Sainsbury, P. and Craig, J. (2007). Consolidated criteria for reporting qualitative research (COREQ): A 32-item checklist for interviews and focus groups. Int J Qual Health Care, 19, 349-357.

Tracy, S. J. (2010). Qualitative quality: Eight "big-tent" criteria for excellent qualitative research. Qual Inq, 16, 837-851.

Yüksel, A., Mil, B. ve Bilim, Y. (2007). Nitel araştırma: Neden, nasıl, niçin. Ankara: Detay Yayıncllk.

\section{Kaynakça Bilgisi / Citation Information}

Tekindal, M., Attepe Özden, S., Gedik, T. E., Ege, A., Erim F. ve Tekindal M. A. (2021). Nitel araştırmaların raporlanmasında standartlar: SRQR Kontrol Listesinin Türkçe uyarlaması. OPUS- Uluslararası Toplum Araştırmaları Dergisi, 18(42), 5425-5443. DOI: 10.26466/opus.882177. 